
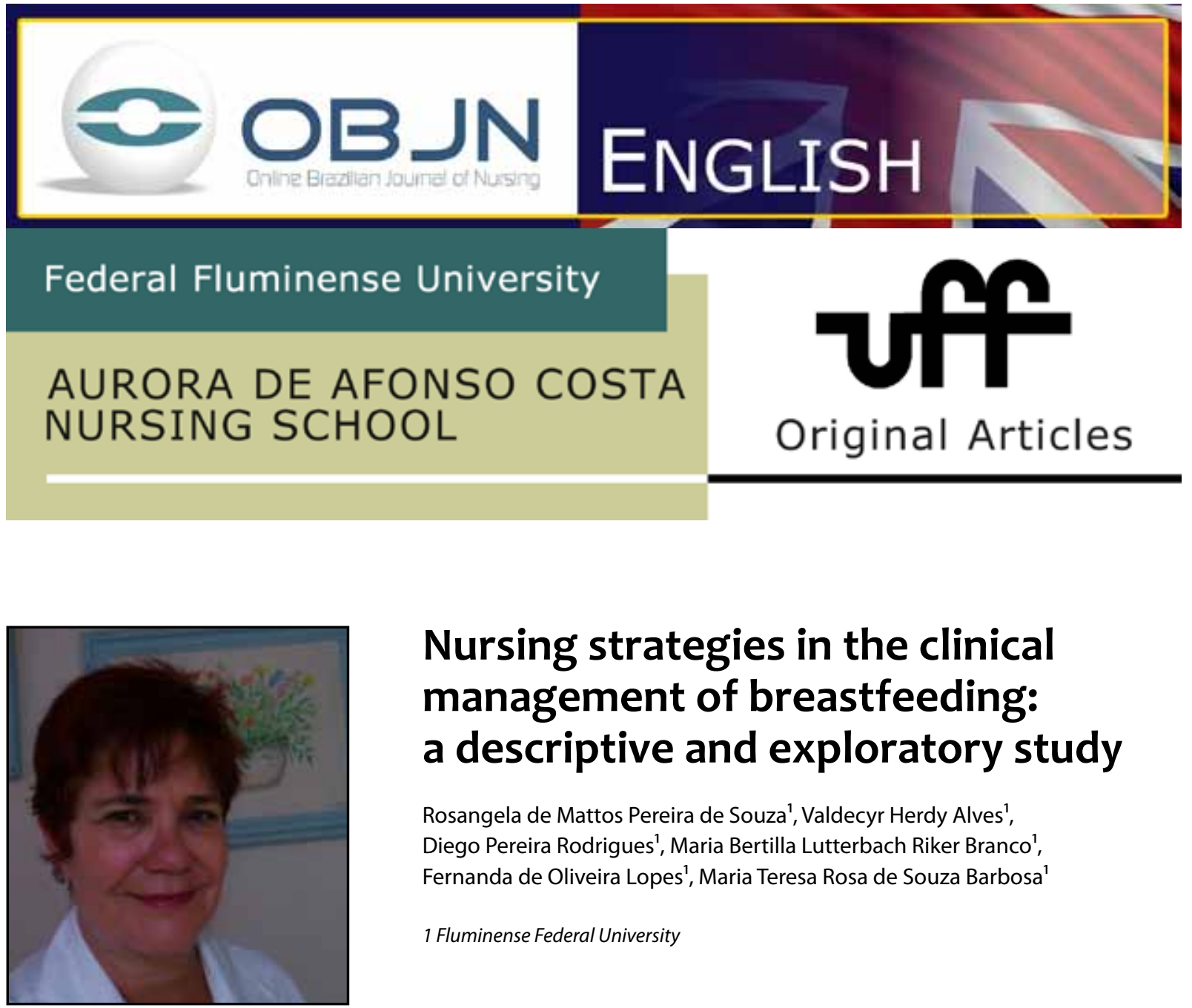

\title{
Nursing strategies in the clinical management of breastfeeding: a descriptive and exploratory study
}

\author{
Rosangela de Mattos Pereira de Souza', Valdecyr Herdy Alves', \\ Diego Pereira Rodrigues', Maria Bertilla Lutterbach Riker Branco', \\ Fernanda de Oliveira Lopes', Maria Teresa Rosa de Souza Barbosa' \\ 1 Fluminense Federal University
}

\section{ABSTRACT}

Aim: To identify the strategies used by nurses regarding the clinical management of breastfeeding; analyze the strategies used by nurses in the conduct of the clinical management of breastfeeding. Method: A descriptive, exploratory, qualitative study which was carried out in public hospitals of the $2^{\text {nd }}$ Metropolitan region of the State of Rio de Janeiro with 107 nurses working at the obstetric center, rooming and ward. Data were collected through semi-structured interviews and analyzed according to the construction of thematic categories. Results: The clinical management of breastfeeding becomes evident like strategy used by nurses to promote breastfeeding and in management of complications and obstacles, allowing the growth of exclusive breastfeeding. Conclusion: In their professional practice, nurses contribute to the health and well-being of women, children and family, promoting skilled and specialized care in the clinical management of breastfeeding.

Descriptors: Breast Feeding; Women's Health; Nursing. 


\section{INTRODUCTION}

Breastfeeding is a socio-cultural and historical process that is influenced by multiple factors linked to the organization of life in society and to personal questions ${ }^{(1)}$. Thus, the promotion, protection and support of breastfeeding have shown significant actions to improve the quality of health of both women and children. However, the overall rates of breastfeeding practices recommended by the World Health Organization (WHO) have remained stagnant over the last decade. This is reinforced by the negligence of government budget and finance departments, which only support actions that promote breastfeeding, and disregard current children's health policies in Brazil, which in addition to promotion, establish the protection and support of breastfeeding ${ }^{(2)}$.

Currently, it appears that the adoption of breastfeeding is not universal due to cultural, social and economic factors. Although research conducted in Brazil demonstrates a growing trend in the rate of breastfeeding, the numbers are still far from the recommended ideal(3). According to the Ministry of Health $(\mathrm{MOH})$, in 2009 , the city of Rio de Janeiro had a prevalence rate of $40.7 \%$ of the exclusive breastfeeding of newborns up to six months of age, a figure much inferior to the ideal, in reaching the quality standards of the promotion, protection and support of breastfeeding ${ }^{(4)}$.

The practice of breastfeeding ensures full, healthy growth and development in the infant, owing to its nutritional values and protection, and promotes bonding between mother and child, contributing to the woman/mother postpartum recovery. The $\mathrm{MOH}$ recommends exclusive breastfeeding for children up to six months of age and supplementary breastfeeding for up to two years ${ }^{(4,5,6)}$.

We observe that social movements in support of breastfeeding have resulted in the change of the health professional praxis in maternity wards directed to the stimulation and support of lactation. Using techniques and strategies according to the clinical management of breastfeeding during the period of female hospitalization, enables the stimulation of breastsuckling, and also helps to establish the practice of breastfeeding ${ }^{(7.8)}$.

In this context, health professionals, especially nurses, must provide safety and comfort for the woman/mother using interventions in the clinical management of breastfeeding, guiding, help in the handling and positioning of breastfeeding, preventing breast complications, and also acting in its promotion, protection and support $^{(9)}$.

Motherhood must provide the appropriate conditions for breastfeeding and its management. The habit of breastfeeding should begin soon after birth and continue throughout rooming.

These practices have been successful, in the form of observing and correcting some problems, such as suckling or handling errors or maternal insecurity, which can interfere in establishing breastfeeding.

In this sense, the Program to Encourage Breastfeeding, established in 1981, stipulated the training of health professionals; media campaigns; breastfeeding counseling; production of educational material; establishment of breastfeeding support groups; marketing control of artificial milk; and legislation to promote, protect and support breastfeeding, making it an important tool for the clinical management of breastfeeding ${ }^{(10)}$.

Currently, the National Policy on Breastfeeding is organized into six main strategies: encouraging breastfeeding in primary care the "Amamenta e Alimenta Brasil" network; the Baby Friendly Hospital Initiative (BFHI) and the 
"Kangaroo Care method" in hospital care; the Brazilian Network of Human Milk Banks; legal protection through the Brazilian Standard for Marketing of Baby Food (NBCAL); actions of social mobilization through campaigns and partnerships; and monitoring of breastfeeding actions and practices.

In this context, the clinical management of breastfeeding in the hospital network includes the Ten Steps to Successful Breastfeeding to develop clinical skills and the competencies of professionals in women's health care.

Given the above, this study aims to identify and analyze the strategies used by nurses in relation to the clinical management of breastfeeding.

\section{METHOD}

This is a descriptive, exploratory study with a qualitative approach, which determines the value of meanings of human relationships in the face of experienced situations.

The research was conducted after approval by the Research Ethics Committee of the Faculty of Medicine of the University Hospital Antônio Pedro, linked to the Fluminense Federal University, under CAEE Protocol number: 0199.0.258.000-11, as provided by Resolution $466 / 12$ of the National Health Council (CNS).

The research scenarios included seven public hospitals in the $2^{\text {nd }}$ Metropolitan Region of the State of Rio de Janeiro: Antonio Pedro University Hospital; Azevedo Lima State Hospital; Dr. Alzira Reis Vieira Municipal Maternity; Hospital da Mulher Gonçalense; Conde Modesto Leal Hospital; Desembargador Leal Junior City Hospital; and Darcy Vargas Regional Hospital.

The sample of the study's participants consisted of 107 nurses. The inclusion criteria were to act in an obstetric ward, rooming and centers. The exclusion criteria took into consideration nurses' leave, sick leave or maternity. All of the participants signed the Informed Consent Form conditioning their voluntary participation in the study. Anonymity and confidentiality of information was ensured by the use of alphanumeric code $\left(E_{1} \ldots E_{107}\right)$.

The participants responded to an individual semi-structured interview consisting of 31 questions, 7 of which focused on identification, working time, specific training of respondents, and standards in the institution; and 19 regarding the clinical management of breastfeeding, adapted from BFHI interview scripts. The interviews were conducted from June 2012 to June 2013 and recorded by a digital device with prior approval of the participants, transcribed and submitted to analysis. Data on age, gender and position in the institution were included in the header.

We opted for a thematic content analysis to verify the various meanings identified in the register units and build thematic categories. The strategy used was to highlight register units with distinct colors in Microsoft Word ${ }^{\circ}$ and group related ones, thus allowing for an overview. After this process, we established a spreadsheet ("demonstrative chart") in a Word ${ }^{\circ}$ document. The coding units were grouped and regrouped by sense, and its percentage rates were analyzed forming themes for each group.

This enabled us to discuss and establish a view to achieve the proposed objectives of the study. As a result, we established the following meaning: The actions of the clinical management of breastfeeding as a care practice for the promotion of women's and children's health: the support of breastfeeding as a strategy for its success.

\section{RESULTS}

The predominant characteristics of the study's participants were female and aged 
between 23 to 58 years, with the following distribution: 4 managers, 8 health assistance coordinators and 95 nurses. Fifty-six nurses reported having received specific training about breastfeeding, 24 mentioned the Baby Friendly Hospital Initiative, 5 cited the BreastfeedingFriendly Unit, 2 mentioned counseling, 14 reported other courses and 11 did not specify the course taken.

The clinical management of breastfeeding actions as care practice of women's and children's health promotion

Given that breast milk is the ideal food for term and preterm infants in early life, especially if exclusive in the first six months of life, we can see in the statements of the respondents the encouragement given to women under their care, demonstrated in a practical way:

(...) Breast milk is the ideal milk for any child. In fact, this milk - mother's [emphasis] - is the essential thing to that child. (E12)

(...) I instruct that the baby must find the whole areola with a wide open mouth, wait for him to open his entire mouth and position the nipple to make him take all the dark part, the areola, so he could have good suction. The lips must be open, like a fish, so he can have perfect breastfeeding. (E24)

Similarly, in their care practice, the nurses promote the benefits of breastfeeding to mothers, identifying and describing that breastfeeding contributes to the contraction and uterine involution, especially when started early. As immediate uterine bleeding after delivery this is an important factor that may contribute to ma- ternal death in the perinatal period. According to one nurse's testimony:

(...) I think it's important, in the time to move the patient if this mother is breastfeeding or not. Because if she is able to breastfeed, I know we're safe enough about her bleeding, but if not breastfeeding (...) I become alert. Checking her Pinard globe, I see her bleeding. It influences my analysis, it's relevant to me. (E67)

Thus, using accessible language during the assistance provided to women/mothers in the immediate postpartum helps in their understanding of the importance of breastfeeding to both their and their child's health, and confirms that the recommended communication, together with counseling techniques, helps to promote breastfeeding. According to the following statement:

(...) The right thing is, when she goes back home, breastfeeding is exclusive, so that the baby, maybe up to the first 6 months of life, is fed only by breast, and after this the ideal is to keep breastfeeding for 2 years. (...) It provides all the necessary nutrients. They usually have a lot of questions about colostrum, "Oh, it's only some water pouring out". Then we explain that colostrum is the initial fluid containing all the fat and all the nutrients the baby needs at that time. As there is more baby feeding, more stimulation, milk production is increased in stages. I explain in a more focused way to their language. (E72)

The immediate promotion of breastfeeding after delivery often permeates the waiting 
process for the results of laboratory tests - such as HIV testing, a limiter in the actions of breastfeeding in the first hour of the baby's life. This fact is expressed by nurses as a limiting routine for the initiation of breastfeeding:

(...) Here we don't have the habit of putting the baby to be fed already in the delivery room, (...) but there are patients who only receive the result of the HIV test on the discharge day, and in the meantime their babies drink artificial milk in the cup. It's when I interfere, rush to the lab, check if the patient has done the exam, I go after the result. If it is negative, she can breastfeed. (E34)

Some distancing situations IS THIS CORRECT? may occur during the hospitalization period with women whose children are hospitalized and who need guidance and help to maintain lactation. The advice to extract, store the milk and supply it to the baby in ways that do not jeopardize continued breastfeeding promote breastfeeding, as stated in the following:

(...) We teach that she has to massage [the breast] to express it, apply pressure to the breast to make the milk come out. (...). I demonstrate, I teach [by] demonstrating. Because here, our experience, we offer the formula, the milk, the artificial diet in the cup, and there's no interference, then the baby takes the breast. The baby suckles the breast when the time comes, when he's able to take the breast, when the mother is able, because sometimes it's the mother who can't, she's recovering from childbirth. (E15)
The support of breastfeeding as a strategy and its success

The use of strategic actions in the clinical management of breastfeeding is evident in the following statement, in which the nurse signaled the use of counseling skills as a starting point for assistance actions, recognizing rooming and hosting as existing strategies that favor the promotion of breastfeeding:

(...) It is empathy [pause], active listening, listening more than talking, to return that communication (...) non-verbal, (...) use the look, expression, contact, positioning near her. (...) Even with the ward too full, there we can choose those at some risk in case we are short on staff, (...) This area belongs to women, children and their family. We are lucky, we work in a ward which allows the presence of a companion, a relative of the woman's choice. Therefore, for us this was one of the best strategies to encourage breastfeeding-allowing a companion, which is a national law. (E1)

Breastfeeding support should be established throughout the puerperal period of pregnancy, and strategies that sustain support for women in coping with difficulties in breastfeeding practices are needed. In this sense, the clinical management of breastfeeding plays an important role and the nurses' statements highlighted the importance of supporting this care, as exemplified in the following excerpt:
(...) Guiding, teaching, always being present at the time the patient is hos- pitalized. Always being by the side of the patient when she is discharged. At home, she can go on. (E67) 
In this context, the support, in the testimonies of nurses about the clinical management of breastfeeding, meets the active listening, and is recognized as a starting point for their assistance actions:

(...) Look, first thing I think, well, is important, is to sit by the mother's side and not to stay in that 'you are the mother and I am professional' position (...) you establish eye contact. I think this time you must have it to know her, and for her to know who she is talking to, and to be confident to share anything with you. (E63)

The nurses described the practical support as a way to ensure the success of breastfeeding, as shown in the following statement:

(...) To assist [is] to keep a good position, to the child's good suckling, seeing if the child is underactive or not, if she is suckling well, or if she's not suckling at all. And sometimes, the staff don't think this work is so important (...) to prevent breast problems. (E12)

The nurses pointed out the importance of having the skills to deal with the different situations that may be an obstacle to breastfeeding:

(...) First, I check if the colostrum is coming out, I help to extract it and ask the mother to put the colostrum in the nipple for the child to taste it. And when I see that the child is having difficulty in latching on, I put on a glove and see if he has the proper suction reflex and latch. Because sometimes the child really has difficulties in finding the latch on position, then I do a bit of stimulation with the glove and then place him on the breast. (E87)

When preparing the mothers to be discharged the nurses included references to monitoring breastfeeding and support. Also, for possible difficulties after discharge they mentioned health centers, nursing rooms and milk banks, or even offered the unit itself for support, as explained below:

(...) We advise avoiding the pacifier. If you need to add something, (...) we advise using the cup (...) because breast milk is important. (...) We give all advice to mothers during discharge. We advise them to go to a milk bank, or even us, in case of any problems, in case of fever or if the baby can't suckle. (E8)

\section{DISCUSSION}

The assistance actions of health professionals, especially nurses, include educational interventions that increase women's knowledge about breastfeeding, facilitating their reflection on its daily practice and the clinical management of its process, and their autonomy and their exercise of citizenship as women ${ }^{(11,12)}$.

Women's perception about this question passes by the actions of health professionals trained in breastfeeding practices, allowing them to see the correct way to practice it, and also turning the process into something pleasurable for their health and for the child. This includes guidance on the benefits of human milk (for their child's well-being and safety), advising that no other food needs to be introduced to the baby's diet until six months of age, and also that their milk is sufficient and nutritious. 
Understanding the influence of health promotion actions and the exclusive use of breastfeeding in nursing practice, we can see how this practice allows simple changes to achieve more direct actions in improving early weaning indicators. It is implied, therefore, that the attitudes of nurses in their promotion of care practices may have an impact on the health of women and children in the biopsychosocial and economic aspects of breastfeeding.

This also covers the Kangaroo care method, an $\mathrm{MOH}$ policy that provides professional training for the health care of preterm infants in neonatal units, reflecting on the active participation of the mother and family in the recovery process of their children's health. This method also includes the promotion and support of breastfeeding in the neonatal unit, contributing to a higher prevalence of breastfeeding at hospital discharge and weight gain in the newborn ${ }^{(13)}$.

Knowledge of the benefits of breastfeeding allows mothers/nurses to understand that breastfeeding stimulates the production of oxytocin from the pituitary gland through the suction stimulus, which favors uterine contraction and inhibits postpartum hemorrhage ${ }^{(14)}$.

Nurses, through the clinical management of breastfeeding in care practices, help mothers to understand about the benefits of human milk for the child. This is an essential food for their welfare, which also stimulates the excretion of hormones that interact in their body, allowing the reduction and inhibition of postpartum hemorrhage; a simple and extremely important practice for reducing maternal mortality.

A lack of understanding regarding the practice of breastfeeding is only seen during breastfeeding itself, as a consequence of doubts, fears, anxiety and insecurity ${ }^{(12)}$. Thus, within their care performance in clinical management, nurses should advise mothers, which contributes to their understanding regarding the impor- tance of breastfeeding for their own and their children's health and promotes a change of behavior, favoring its practice. The use of simple terms is essential in establishing an exchanging and facilitator relationship with regard to breastfeeding, guiding and answering questions, always recognizing and respecting any limitations to understanding.

The recommendations of the $\mathrm{WHO}$ and $\mathrm{MOH}$ recommend that breastfeeding is initiated in the first hour after birth, favoring a reduction in risk of neonatal mortality ${ }^{(4,5)}$. However, a delay in the rapid delivery of HIV test results often becomes a limiting factor in the actions of nurses in meeting the ten steps to successful breastfeeding, specifically step 4 from the $\mathrm{BFHI}^{(4,15)}$.

To show how nursing mothers can breastfeed and maintain lactation, even when separated from their children (step 5 of BFHI), involves demonstrating and helping with the latch-on position for breastfeeding and expressing milk; this being the last critical factor to maintain lactation and reduce the risk of breast complications ${ }^{(15)}$.

In this perspective, nurses should guide and demonstrate maneuvers to express milk to mothers so they can be performed when feeding their children, as well as for disease prevention such as breast engorgement.

The baby must be fed with the mother's own milk. The alternative to this practice in the intensive care unit would be its administration by the cup, aimed at preventing the early contact of the newborn with nipples other than the breast, preventing confusion that favors early weaning.

The actions of the clinical management of breastfeeding described by nurses are a result of planning and decision making for the promotion of breastfeeding to nursing mothers. These using care technologies for active communication that support the initiation of breastfeeding, and thus when discharged from hospital offer guidance 
and referral to a support network in order to continue this practice. However, despite the limitations encountered by nurses in relation to the HIV rapid test, acts of clinical management in breastfeeding are based in a discourse favoring the initiation of breastfeeding and recognizing women as the main subjects who have this right.

Breastfeeding counseling are the practices of health professionals targeted at the mother in which they listen, try to understand her and, with their knowledge, offer help in providing planning, decision-making and strengthening their ability to deal with pressure, increasing the mother's confidence and self-esteem. Therefore, it is important to use counseling techniques concurrently with the first feeding and during rooming-in $^{(16,17)}$.

Therefore, nurses should perform the clinical management of breastfeeding with a good relationship between the professional and mother: with communication, listening and understanding, interacting with her about clinical management, and also identifying the real needs of the various mother/child problems. This approach is essential in the professional's relationship with the mother, because it allows the hosting practice to be as effective for the promotion of breastfeeding as for women's rights.

Nurses must have strategies to support breastfeeding and to cope with the difficulties of the act of breastfeeding. Therefore, counseling is a strategy to provide care for the mother. To resolve doubts and difficulties, the nurse asks the mother to simulate the technique of breastfeeding and talks about its importance and benefits. In this way, nurses promote and support breastfeeding, and change the reality of the mothers, implementing behavior change through reflective and constructive actions during counseling ${ }^{(17)}$.

Counseling as a practice and technique is of paramount importance and substantial relevance in allowing the health professional to have the opportunity of performing not only educational, but also assistance actions in the common illnesses at the beginning of breastfeeding. For example, breast engorgement, which sometimes can lead to early weaning and is caused mainly by difficulties in the latch-on position, poor posture and nipple pain ${ }^{(18)}$.

In this perspective, nurses have the possibility of using counseling as a strategy to provide care for nursing mothers, promoting support for exclusive breastfeeding, as well as perpetuating the benefits of breastfeeding and remedying difficulties in its practice.

Active listening is a nursing strategy for the clinical management of breastfeeding, and is a dynamic, interactive and welcoming process. Listening is different from hearing; it is more than perceiving sounds by auditory perception. It sets up an emotional, cognitive, active and complex process that extends from auditory perception, and considers the attention, interest and motivation aspects. It demands of the subject more than the simple passivity of not talking; it involves applying attention to hearing, seeking to understand the other, and considering that there is more meaningful context behind the words spoken $^{(19)}$.

Thus, the act of hearing remains a nurse's strategy for the clinical management of breastfeeding, demanding a quality time to identify the real difficulties of women/nursing mothers towards successful breastfeeding, to ensure their autonomy and confidence.

Support for successful breastfeeding should comprise of the nursing practice, as problems related to improper positioning of the mother and baby hinder the relationship between the child's mouth and the nipple, which interferes with the latch-on and the expressing of milk ${ }^{(20)}$. Correcting the latch-on position must be linked to supporting breastfeeding in the nur- 
sing praxis of everyday life, avoiding problems such as sore nipples, cracks and breast engorgement, which complicates the establishment and success of breastfeeding. In addition, providing guidance during pregnancy and childbirth in order to avoid such problems, which together interfere in the suction dynamics and milk expressing, certainly hinder the establishment of breastfeeding practices ${ }^{(21)}$.

In this context, the support of qualified and experienced personnel in the practice of breastfeeding is extremely important, as it allows the implementation of support as a strategy for successful breastfeeding.

The art of breastfeeding, day after day, becomes an obstacle for women. The nurse, promoting strategies in the clinical management of breastfeeding, conveys the importance of these actions and their contribution to breastfeeding. The engaged professional develops skills in order to significantly demonstrate the benefits of breastfeeding to the mother, her baby and family, showing its value, how it should be done, the child's suction stimulus, the prevention of complications and provides support and orientation, especially with expressing the milk. This nursing praxis is essential to promote maternal and children's well-being and health, contributing to the reduction of early weaning and maternal mortality.

Special services such as human milk banks in the clinical management of breastfeeding, with care protocols to promote these effectively and satisfactorily for both the mother and baby, also encourages the family's participation in the process $^{(4,8,10)}$. In this context, discharge from hospital can become an obstacle to the continuation of breastfeeding for mothers at home. At these times, nurses must guide mothers about services that can help, such as the Human Milk Bank, Breastfeeding Centers, Breastfeeding-Friendly Primary Care Units, and offer support when fa- cing difficulties related to breastfeeding. These guidelines will allow the mother to understand her ability to promote and support breastfeeding outside the hospital setting, because difficulties and complications can be managed and treated at a specialized service.

It can be inferred that breastfeeding success permeates the strategic actions used in the clinical management of breastfeeding as a means to consolidate the support to the mother/nurse. Thus, nurses play an important role in the field of breastfeeding, supporting and promoting breastfeeding during the mother's hospitalization.

\section{CONCLUSION}

Nurses play a key role in the clinical management of breastfeeding and are essential for the promotion of its practice with women/ nursing mothers in maternity hospitals. In its practice, they emphasize the importance of breastfeeding, its advantages and benefits for the health of babies (because it is the best food for them) and, in this way, they work in favor of exclusive breastfeeding, meeting public policies about breastfeeding activities in the country.

In breastfeeding, the nurse should be a facilitator of this practice in caring for the mother, providing advice about the beginning of breastfeeding, its maintenance and continuity.

The use of counseling technique by nurses, their knowledge and educational approaches, are vital for the promotion of breastfeeding, inhibiting obstacles and resolving problems related to its practice. However, it must be conducted in a warm and humane way, with active listening to the women's desires and experiences of breastfeeding, so that it can be successful and, above all, maintained. 


\section{REFERENCES}

1. Moreira MA, Nascimento ER, Paiva MS. Social representations concerning the breastfeeding practices of women from three generations. Texto Contexto Enferm. 2013; 22(2): 432-41.

2. Teixeira MA, Nitschke RG. Modelo de cuidar em enfermagem junto às mulheres-avós e sua família no cotidiano do processo de amamentação. Texto Contexto Enferm. 2008; 17(1): 183-91.

3. Muller FS, Silva IA. Social representations about support for breastfeeding in a group of breastfeeding women. Rev Latino am Enferm [Internet]. 2009 [citado em 02 out 2013]. 17(5): 651-7. Available from: http://www.scielo.br/ scielo.php?script=sci_arttext\&pid=S0104$-11692009000500009 \&$ Ing=pt\&nrm=iso\&tlng $=$ en

4. Brasil. Ministério da Saúde. Secretária de Atenção à Saúde. II Pesquisa de prevalência de aleitamento materno nas capitais brasileiras e distrito federal. Brasília: Ministério da Saúde; 2009.

5. Toma TS, Rea MR. Benefícios da amamentação para a saúde da mulher e da criança: um ensaio sobre evidências. Cad. Saúde Pública [Internet]. 2008 [citado em 02 out 2013]. 24(sup 2): 235-46. Disponivel em:http://www.scielo.br/pdf/csp/ v24s2/09.pdf

6. Carvalho MR, Tavares LAM. Amamentação: bases científicas. 3. ed. Rio de Janeiro: Guanabara Koogan; 2010.

7. Caminha MFC, Serva VB, Arruda IKG, Filho MB. Aspectos históricos, cientificos, socioeconômicos e institucionais do aleitamento materno. Rev Bras Saude Mater Infant [Internet]. 2010 [citado em 02 out 2013]. 10(1): 25-37. Disponivel em: http:// www.scielo.br/pdf/rbsmi/v10n1/v10n1a03.pdf

8. Brasil. Ministerio da Saúde. Agência Nacional de Vigilância Sanitária. Banco de leite humano: funcionamento, prevenção e Controle de Riscos. Brasília: Ministerio da Saúde; 2008.

9. Lara $A C L$, Fernandes RAQ. Quality of life in the mediate postpartum: a quantitative study. Online Braz J Nurs (Online) [Internet]. 2010 [citado em 25 nov 2013]. 9(1). Available from: http://www. objnursing.uff.br/index.php/nursing/article/ view/j.1676-4285.2010.2815/643
10. Alencar SMS. O aleitamento materno no contexto atual: Políticas, práticas e bases científicas. São Paulo: Sarvier; 2008.

11. Silveira MMM, Barbosa NB. Aleitamento materno no município de Anápolis: saberes e práticas na Estratégia Saúde da Família. Rev APS. 2010; 13(4): 445-55.

12. Alves MRS, Ferreira SCM, Andrade M. Nursing consultation in homecare for the milk bank of Antonio Pedro College Hospital: a space for educative actions. Online Braz J Nurs (Online) [Internet]. 2013 [citado em 25 nov 2013] 12(esp.). Available from: http://www.objnursing.uff.br/ index.php/nursing/article/view/4536/pdf

13. Gontijo TL, Xavier CC, Freitas MIF. Avaliação da implantação do Método Canguru por gestores, profissionais e mães de recém-nascidos. Cad. Saúde Pública. 2012; 28(5): 935-44.

14. Rezende J. Obstetrícia. $12^{\mathrm{a}}$ ed. Rio de Janeiro: Guanabara Koogan; 2013.

15. Almeida GG, Spiri WC, Juliani CMCM, Paiva BSR. Proteção, promoção e apoio ao aleitamento materno em um hospital universitário. Ciênc Saúde Coletiva. 2008; 13(2): 487-94.

16. Athanázio AR, Lopes JC, Soares KFMS, Góes FGB, Rodrigues DP, Rodrigues EMS. The importance of nurses in encouraging breastfeeding in the glass to the newborn: integrative review. J Nurs UFPE online [internet]. 2013 [citado em 25 nov 2013]. 7(esp). Available from: http://www.revista.ufpe. br/revistaenfermagem/index.php/revista/article/ view/4279/pdf_2587

17. Brandão EC, Silva GRF, Gouveia MTO, Soares LS. Caracterização da comunicação no aconselhamento em amamentação. Rev Eletr Enf [Internet]. 2012 [citado em 02 out 2013]. 14(2): 355-65. Available from: http://www.fen.ufg.br/revista/ v14/n2/v14n2a16.htm

18. Quirino LS, Oliveira JD, Figueiredo MFER, Quirino GS. Significado da experiência de não amamentar relacionado às intercorrências mamárias. Cogitare Enferm. 2011; 16(4): 628-33.

19. Araújo MMT, Silva MJP. O conhecimento de estratégias de comunicação no atendimento à dimensão emocional em cuidados paliativos. Texto Contexto Enferm. 2012; 21(1): 121-9.

20. Marques RFS, Cunha ICC, Aragón MG, Peixoto VS. Fatores relacionados às dificuldades no 
aleitamento materno entre mãe adolescente da Fundação Santa Casa de Misericórdia do Pará. Rev Pará Med. 2008; 22(1):57-62.

21. Fujimori E, Nakamura E, Gomes MM, Jesus LA, Rezende MA. Aspectos relacionados ao estabelecimento e à manutenção do aleitamento materno exclusivo na perspectiva de mulheres atendidas em uma unidade básica de saúde. Interface comum saúde educ. 2010; 14(33):315-27.
All authors participated in the phases of this publication in one or more of the following steps, in According to the recommendations of the International Committee of Medical Journal Editors (ICMJE, 2013): (a) substantial involvement in the planning or preparation of the manuscript or in the collection, analysis or interpretation of data; (b) preparation of the manuscript or conducting critical revision of intellectual content; (c) approval of the versión submitted of this manuscript. All authors declare for the appropriate purposes that the responsibilities related to all aspects of the manuscript submitted to OBJN are yours. They ensure that issues related to the accuracy or integrity of any part of the article were properly investigated and resolved. Therefore, they exempt the OBJN of any participation whatsoever in any imbroglios concerning the content under consideration. All authors declare that they have no conflict of interest of financial or personal nature concerning this manuscript which may influence the writing and/or interpretation of the findings. This statement has been digitally signed by all authors as recommended by the ICMJE, whose model is available in http://www. objnursing.uff.br/normas/DUDE_eng_13-06-2013.pdf

Received: $1 / 9 / 2014$

Revised: 12/23/2014

Approved: 12/23/2014 